\title{
A CONDENAÇÃO EM HONORÁRIOS SUCUMBENCIAIS NA JUSTICCA DO TRABALHO SOB A ÓTICA DA LEI № 13.467/17
}

http://dx.doi.org/10.21527/2176-6622.2021.55.34-40

Recebido em: 24/4/2019

Aceito em: 4/11/2020

Brenno Augusto Freire Menezes

Autor correspondente. Ministério Público do Trabalho. Av. Pres. Dutra, 4055 - Olaria, 76801-327. Porto Velho/RO, Brasil. http://lattes.cnpq.br/1113626419044543. https://orcid.org/0000-0001-6813-2163 brennofreire19@live.com

\section{Mariése Garcia Costa Rodrigues de Alencar}

Centro Universitário Estácio de Sergipe. Aracaju/SE, Brasil.

\section{RESUMO}

A pesquisa apresentada neste artigo busca analisar os aspectos positivos e negativos da condenação em honorários sucumbenciais na Justiça do Trabalho, considerando as alterações na Consolidação das Leis do Trabalho, provenientes da entrada em vigor da Lei n. 13.467 de 2017. Atualmente, no que se refere à temática, o novo texto da CLT prevê a possibilidade de condenação em honorários advocatícios sucumbenciais em todas as relações de trabalho, inclusive nas relações de emprego, indo de encontro ao entendimento dominante da doutrina e dos tribunais, incluindo o TST, até 2017. Mesmo, todavia, sendo o posicionamento minoritário, antes das alterações já existia uma tímida jurisprudência nos Tribunais Regionais do Trabalho do país no sentido favorável à condenação em honorários sucumbenciais, embasando o seu posicionamento na aplicação subsidiária do artigo 389 do Código Civil. A referida pesquisa pretender analisar os pontos positivos e negativos da efetivação de tal condenação, bem como a constitucionalidade das alterações.

Palavras-chave: Condenação. Honorários sucumbenciais. Justiça do Trabalho.

\section{DAMAGE IN FELLS SUCUMBENTIALS IN LABOR JUSTICE UNDER THE LAW OPTICS N 13.467/2017}

\section{ABSTRACT}

The research presented in this article intends to analyze the positive and negative aspects of the sentenced in attorney's fees in the Labor Court, considering the changes in the Consolidation of Labor Laws, coming from the entry into force of Law n. 13,467 out of 2017. Currently, concerning this thematic, the new text of the CLT, law 13467/17, provides for the possibility of such condemnation in all labor relations, including employment relations, which was contrary to the majority understanding of the Doctrine and Courts, including the TST, until 2017. However, even being a minority position, previously to the law modification, there was already a timid case law in the country's Regional Labor Courts in favor of sentenced in attorney's fees, based on its position in the subsidiary application of articles 389 of the Civil Code. This research intends to analyze the positives and negatives of the effectiveness of such sentence, as well as the constitutionality of those modifications.

Keywords: Sentence. Attorney's fees. Labor Justice.

\section{SUMÁRIO}

1 Introdução. 2 Breve histórico acerca da condenação dos honorários na Justiça do Trabalho. 3 As alterações provenientes da reforma trabaIhista no que se refere à condenação em honorários sucumbenciais. $3.1 \mathrm{~A}(\mathrm{In})$ constitucionalidade do artigo da lei que trata dos honorários. 4 Aspectos positivos e negativos da condenação em honorários sucumbenciais de acordo com o texto da nova reforma trabalhista. 5 Considerações finais. 6 Referências. 


\section{INTRODUÇÃO}

O tema dos honorários sucumbenciais era bastante polêmico nos domínios do processo do trabalho, tendo em vista que existia um forte dissenso doutrinário e jurisprudencial sobre a matéria, com a formação de duas correntes. Com a reforma trabalhista, decorrente das alterações trazidas pela Lei n. 13.467 de 2017, porém, esse cenário sofreu importantes alterações, conforme será tratado posteriormente.

Nesse contexto, antes da vigência da nova lei trabalhista existiam duas correntes acerca da condenação em honorários advocatícios na Justiça do Trabalho; uma delas, encabeçada pelo Tribunal Superior do TrabaIho, trazia no bojo das suas súmulas 219 e 329, o entendimento de que, em regra, os honorários sucumbenciais não eram cabíveis na justiça laboral. Assim, a possibilidade da condenação em honorários sucumbenciais pelo vencido somente era admitida em hipóteses excepcionais, por exemplo, em casos em que a parte era beneficiária da assistência judiciária gratuita, desde que assistida pelo sindicato profissional, com condenação fixada de $10 \%$ a $20 \%$.

A segunda corrente acerca do assunto, cujo posicionamento era minoritário, entendia que os honorários advocatícios na Justiça do Trabalho, em caso de sucumbência, seriam sempre devidos ao advogado, tendo em vista o disposto no artigo $133^{1}$ da Constituição Federal e nos artigos 84 e 85 do Código de Processo Civil, ${ }^{2}$ os quais são aplicados de forma subsidiária no Direito Processual do Trabalho. Além dos dispositivos citados, os defensores dessa corrente fundamentavam o seu entendimento ainda no artigo 22 da lei 8.906 de 1994, ${ }^{3}$ que dispõe que a prestação de serviço profissional assegura aos inscritos na $\mathrm{OAB}$ o direito aos honorários convencionados tanto por decisão judicial quanto por sucumbência.

Diante do dissenso jurisprudencial e doutrinário acerca do assunto e das alterações provenientes da Lei n. 13.467 de 2017, o presente artigo tem o objetivo de apresentar, por meio de uma linha do tempo, a temática dos honorários na Justiça do Trabalho. Assim, pretende-se apresentar o entendimento, que vinha sendo adotado pelo Tribunal Superior do Trabalho, por meio de súmulas que restringiam vultuosamente a condenação dos honorários na justiça laboral, e o entendimento atual acerca do assunto, com a nova redação apresentada pela reforma trabalhista, que ampliou notavelmente o rol de possibilidades desse tipo de condenação.

Nesse sentido, buscar-se-á realizar uma análise detalhada acerca do assunto, verificando os seus pontos positivos e negativos, principalmente considerando que tal temática sofreu grandes alterações em todos os seus pontos, razão pela qual este estudo será feito considerando também a discussão acerca da constitucionalidade das recentes alterações.

Cumpre salientar que para o desenvolvimento deste artigo foram levantadas informações em diversas fontes, dentre elas a Consolidação das Leis Trabalhistas e a jurisprudência dos Tribunais Superiores, além de obras doutrinárias e artigos jurídicos que abordam o tema em questão.

\footnotetext{
Ressalte-se que, conforme redação do artigo 133 da Lei Maior, "o advogado é indispensável a administração da justiça, sendo inviolável por seus atos e manifestações no exercício da profissão, nos limites da lei".

2 Com relação ao atual Código de Processo Civil, os seus artigos 84 e 85 estabelecem que a sentença condenará o vencido a pagar ao vencedor as despesas que antecipou e os honorários advocatícios, conforme redação a seguir.

Art. 84 - As despesas abrangem as custas dos atos do processo, a indenização de viagem, a remuneração do assistente técnico e a diária de testemunha.

Art. 85 - A sentença condenará o vencido a pagar honorários ao advogado do vencedor.

3 Artigo 22 da lei 8.906/94 - A prestação de serviço profissional assegura aos inscritos na OAB o direito aos honorários convencionados, aos fixados por arbitramento judicial e aos de sucumbência.

$\S 1$ O O advogado, quando indicado para patrocinar causa de juridicamente necessitado, no caso de impossibilidade da Defensoria Pública no local da prestação de serviço, tem direito aos honorários fixados pelo juiz, segundo tabela organizada pelo Conselho Seccional da OAB, e pagos pelo Estado.

$\S 2$ 2 Na falta de estipulação ou de acordo, os honorários são fixados por arbitramento judicial, em remuneração compatível com o trabalho e o valor econômico da questão, não podendo ser inferiores aos estabelecidos na tabela organizada pelo Conselho Seccional da OAB.

§ 3오 Salvo estipulação em contrário, um terço dos honorários é devido no início do serviço, outro terço até a decisão de primeira instância e o restante no final.

$\S 4$ ㅇ Se o advogado fizer juntar aos autos o seu contrato de honorários antes de expedir-se o mandado de levantamento ou precatório, o juiz deve determinar que lhe sejam pagos diretamente, por dedução da quantia a ser recebida pelo constituinte, salvo se este provar que já os pagou.

$\S 5$ o 0 disposto neste artigo não se aplica quando se tratar de mandato outorgado por advogado para defesa em processo oriundo de ato ou omissão praticada no exercício da profissão.
} 


\section{Debate}

\section{BREVE HISTÓRICO ACERCA DA CONDENAÇÃO DOS HONORÁRIOS NA JUSTIÇA DO TRABALHO}

No Brasil, a discussão a respeito dos honorários advocatícios de sucumbência surge a partir da vigência do Código de Processo Civil de 1939, derivado do princípio da integralidade da reparação do dano.

O instituto dos honorários sucumbenciais, contudo, não era considerado aplicável à Justiça do Trabalho, porque nela prevalecia o jus postulandi, não sendo obrigatória a presença de advogado nas reclamações trabalhistas (CASTRO, 2017, p. 13).

O processo civil, em relação ao processo do trabalho, sempre tratou de forma diferente os honorários sucumbenciais, considerando estes de natureza alimentar, aplicando-lhe em qualquer situação a sucumbência, de forma diferente do processo trabalhista, que sempre trouxe restrições à condenação em honorários sucumbenciais, principalmente no tocante às relações de emprego.

O entendimento do Tribunal Superior do Trabalho, majoritário até a vigência da Lei no 13.467 de 2017, era sustentado pelas súmulas $219^{4}$ e 329 do egrégio Tribunal, e previa que os honorários advocatícios sucumbenciais na justiça do trabalho só seriam cabíveis nas relações diversas da de emprego.

Nas relações de emprego, em regra, os honorários eram meramente contratuais. Existiam, no entanto, duas situações em que os honorários eram sucumbenciais, excepcionando essa regra: Quando o empregado fosse beneficiário da justiça gratuita e estivesse assistido por sindicato da categoria profissional ou quando o sindicato atuasse como substituto processual. Em tais situações os honorários eram arbitrados inicialmente no percentual de $15 \%$, passando ao percentual de $10 \%$ a $20 \%$ sobre o valor da condenação, após a entrada em vigor do Código de Processo Civil de 2015.

Ao mesmo tempo, uma segunda e minoritária corrente vinha apoiando os honorários sucumbenciais em todas as relações de trabalho, inclusive a de emprego, em qualquer situação, com fulcro no artigo 133 da Constituição Federal, artigos 84 e 85 do Código de Processo Civil e o artigo 22 da lei 8.906/94, sustentando a importância dos honorários advocatícios considerados verba de natureza alimentar.

Nesse sentido, Leone Pereira (2017, p. 191) afirmava que esse impasse, defendido pelo TST, acabava por prejudicar os empregados, uma vez que o único meio de remuneração dos advogados contratados por eles era os honorários contratuais, que, normalmente, eram pactuados em contrato do recebimento do valor máximo (30\%) sob o valor da condenação, diminuindo os valores percebidos pelo trabalhador.

Diante de tal impasse, já existiam entendimentos que permitiam ao juiz de primeiro grau condenar a empresa vencida a arcar com os honorários contratuais, com o intuito de assegurar ao trabalhador a inteira reparação do dano, embasado nos artigos 389 e 404 do Código Civil.

Alguns magistrados atuantes no 10 grau da justiça do trabalho, mas precisamente presentes no corpo do egrégio Tribunal Regional do Trabalho da 20a Região, detinham o entendimento no sentido do cabimento da condenação do reclamado no pagamento dos honorários estabelecidos no contrato firmado entre o empregado e o seu advogado de forma indenizatória na justiça do trabalho nas relações de emprego.

\footnotetext{
Súmula no 219 do TST - HONORÁRIOS ADVOCATÍCIOS. CABIMENTO (alterada a redação do item I e acrescidos os itens IV a VI em decorrência do CPC de 2015) - Res. 204/2016, DEJT divulgado em 17, 18 e 21.03.2016. I - Na Justiça do Trabalho, a condenação ao pagamento de honorários advocatícios não decorre pura e simplesmente da sucumbência, devendo a parte, concomitantemente: a) estar assistida por sindicato da categoria profissional; b) comprovar a percepção de salário inferior ao dobro do salário mínimo ou encontrar-se em situação econômica que não lhe permita demandar sem prejuízo do próprio sustento ou da respectiva família. (art. 14, § 1으, da Lei no 5.584/1970). (ex-OJ no 305da SBDI-I). II - É cabível a condenação ao pagamento de honorários advocatícios em ação rescisória no processo trabalhista. III - São devidos os honorários advocatícios nas causas em que o ente sindical figure como substituto processual e nas lides que não derivem da relação de emprego. IV - Na ação rescisória e nas lides que não derivem de relação de emprego, a responsabilidade pelo pagamento dos honorários advocatícios da sucumbência submete-se à disciplina do Código de Processo Civil (arts. 85, 86, 87 e 90). V - Em caso de assistência judiciária sindical ou de substituição processual sindical, excetuados os processos em que a Fazenda Pública for parte, os honorários advocatícios são devidos entre o mínimo de dez e o máximo de vinte por cento sobre o valor da condenação, do proveito econômico obtido ou, não sendo possível mensurá-lo, sobre o valor atualizado da causa (CPC de 2015, art. 85, § 20). VI - Nas causas em que a Fazenda Pública for parte, aplicar-se-ão os percentuais específicos de honorários advocatícios contemplados no Código de Processo Civil.
} 
Dentre os que se posicionavam nesse sentido, destaca-se a magistrada Cinthia Lima de Araújo do TRT da 20a Região. No momento de arbitrar referida indenização, a juíza embasava sua decisão com fulcro no artigo 389 do Código Civil, como pode ser observado a seguir.

\section{HONORÁRIOS CONTRATUAIS OU INDENIZAÇÃO DAS DESPESAS COM ADVOGADO.}

O artigo 389 do $C C B / 2002$ consagrou o princípio da restituição integral das perdas e danos, impõe-se uma mudança de perspectiva quanto ao ressarcimento da despesa com advogado particular a que o empregado fica compelido, diante do descumprimento da lei trabalhista, a fim de mover a máquina judiciária para promover o recebimento dos seus créditos.

A faculdade de agir pessoalmente na Justiça do Trabalho (jus postulandi - artigo 791 da CLT) ou ser assistido por seu sindicato não obriga as partes a isso. Por outro lado, a estrutural sindical no país revela-se deficitária, não sendo capaz de atender à demanda por assistência judiciária gratuita atual.

Assim, desde que o autor esteja acompanhado de advogado particular, impõe-se a restituição integral desse valor, como regra de justiça e equidade. Embora não haja prova do percentual de honorários advocatícios contratados, segue-se a prática forense de $20 \%$ sobre o valor líquido da condenação. Dessa forma, defiro o pedido.

A referida decisão demonstra uma progressividade não só no fortalecimento da ideia de reconhecimento da natureza alimentar dos honorários advocatícios, mas também uma preocupação com os prejuízos sofridos pelo empregado, sujeito hipossuficiente nas relações de emprego.

Em que pese a progressividade da decisão, porém, a mesma quase sempre foi rechaçada quando reavaliada no $2 \circ$ grau e, nas difíceis vezes que acatada por algum desembargador, acabava sendo rejeitada nos julgados dos ministros do Tribunal Superior do Trabalho. Apesar de tanta rejeição, daqueles que acreditavam nessa ideia, jamais deixou de seguir o seu posicionamento, e, durante muitos anos, até o dia da vigência da nova lei, continuaram aplicando o seu entendimento.

Por fim, alguns doutrinadores também já vinham defendendo, em suas obras jurídicas, outras possibilidades da condenação em honorários sucumbenciais previstas de forma limitada ou não incluídas nas súmulas, por exemplo, a condenação em honorários advocatícios sucumbenciais nas ações acidentárias. Tal situação não estava prevista na redação das súmulas, mas colaborou, posteriormente, na alteração do entendimento jurisprudencial do próprio tribunal (LEITE, 2017, p. 928).

Um dos pontos mais relevantes trazidos no bojo da reforma trabalhista de 2017, todavia, diz respeito às alterações quanto à possibilidade de condenação em honorários sucumbenciais na justiça laboral no que contende às relações de emprego.

\section{AS ALTERAÇÕES PROVENIENTES DA REFORMA TRABALHISTA NO QUE SE REFERE À CONDENAÇÃO EM HONORÁRIOS SUCUMBENCIAIS}

É notório que, mesmo com a prevalência do entendimento do Tribunal Superior do Trabalho sobre a aplicação dos honorários advocatícios na justiça do trabalho, alguns doutrinadores e magistrados já embasavam suas ideias de forma diferente, fortalecendo a concepção da natureza alimentar dos honorários advocatícios.

A reforma trabalhista, vigente a partir de novembro de 2017, no entanto, trouxe no seu bojo significantes mudanças no que se refere à condenação em honorários sucumbenciais na justiça do trabalho. Todas as considerações supracitadas devem ser reexaminadas em razão do artigo 791-A da CLT, acrescentado pela Lei n. $13.467 / 2017$.

A primeira delas prevê a condenação em todas as relações de trabalho, inclusive as de emprego, em favor do advogado, ainda que atue em causa própria, fixados entre $5 \%$ e $15 \%$ sobre o valor da condenação, ou seja, do proveito econômico obtido. Destaca a nova lei que também serão devidos os honorários sucumbenciais na reconvenção.

O §1으, do supramencionado dispositivo legal, consolidou o entendimento de que cabe, inclusive, honorários sucumbenciais perante a Fazenda Pública, bem como nos processos em que a parte estiver assistida ou substituída pelo sindicato de sua categoria, seguindo a inteligência do novel CPC, que, em 2015, alterou a redação da Súmula no 219, do TST (TEIXEIRA FILHO, 2017, p. 86). 
Cumpre salientar, ainda, que, ao fixar os honorários, o juízo observará as seguintes condições: o grau de zelo do profissional, o lugar de prestação do serviço, a natureza e a importância da causa e o trabalho realizado pelo advogado, bem como o tempo exigido para o seu serviço.

É importante destacar, também, que, na hipótese de procedência parcial, o juízo arbitrará honorários para ambas as partes litigantes, sendo vedada a compensação entre as partes.

Por fim, ressalta o novo texto trabalhista que, vencido o beneficiário da justiça gratuita e que, caso litigue em outras demandas e não alcance créditos suficientes para saldar sua condenação sucumbencial, sua dívida ficará suspensa por dois anos. Ultrapassado tal lapso temporal e permanecendo na situação de hipossuficiente, o reclamante terá sua dívida extinta.

Dessa forma, continua existindo a faculdade do jus postulandi das próprias partes, aplicando-se, no que couber, a Súmula 219 do TST. Caso, entretanto, elas estejam litigando com o patrocínio de advogado, a este serão devidos honorários advocatícios nos termos do artigo 791-A da CLT.

\subsection{A (In)Constitucionalidade do Artigo da Lei que Trata dos Honorários}

Um ponto controverso, após a aprovação da nova lei trabalhista, diz respeito à (in)constitucionalidade da condenação em honorários de sucumbências na justiça do trabalho nas relações de emprego, com a alegação de que tal condenação prejudicará o hipossuficiente da relação de emprego. Alguns doutrinadores entendem que esse ponto, trazido na reforma, encontra-se eivado de vício de inconstitucionalidade, porém, de fato, isso não acontece; são vários os argumentos que podem comprovar que não lhes cabe razão, como pode ser analisado a seguir.

Entende parte da doutrina que as normas constantes do artigo 791-A, caput e §§ 1ํaté 5ㅇ, da CLT - se lido em sua literalidade -, podem dificultar o acesso ao direito e às garantias constitucionais fundamentais da justiça gratuita (artigo 50, XXXV, CF), bem como pode violar o direito, garantia e princípio fundamentais do amplo acesso à justiça (artigo 5, XXXV, CF), relativamente à grande maioria das pessoas físicas trabalhadoras do país (GODINHO, 2017, p. 328).

O referido entendimento leva em consideração os elevados riscos econômico-financeiros que passam a envolver as pessoas detentoras de ínfimas rendas, que, normalmente, no processo do trabalho, é o hipossuficiente da relação jurídica processual.

Tal inconstitucionalidade, porém, não merece prosperar, uma vez que os honorários sucumbenciais são necessários nessa seara do direito em todas as suas relações, inexistindo inconstitucionalidade, e, pelo contrário, protegendo direitos fundamentais previstos na Constituição Federal vigente em nosso ordenamento jurídico.

O advogado, como se observa no artigo 133 da Constituição Federal, "é indispensável à administração da justiça, sendo inviolável por seus atos e manifestações no exercício da profissão, nos limites da lei". Além disso, a Lei Maior sustenta como um de seus fundamentos os valores sociais do trabalho e da livre-iniciativa.

É importante destacar, também, a natureza alimentar dos honorários advocatícios, sejam eles contratuais ou sucumbenciais. $\mathrm{O}$ atual Código de Processo Civil, ao abordar o assunto, trata a referida verba como alimentar, conforme dispõe o seu artigo 85, §14: "Os honorários constituem direito do advogado e têm natureza alimentar, com os mesmos privilégios dos créditos oriundos da legislação do trabalho, sendo vedada a compensação em caso de sucumbência parcial".

Vale ressaltar, ainda, o posicionamento do Superior Tribunal de Justiça acerca da matéria. Em que pese não ter competência sob a justiça laboral, o STJ já reconheceu devidamente a natureza alimentar dos honorários em diversos julgados, por meio de inúmeros Recursos Especiais, tais como o REsp 706331/PR e o REsp 1.152.218/RS.

No mesmo sentido, entende o Supremo Tribunal Federal, guardião da Constituição Federal, que os honorários advocatícios, sejam eles sucumbenciais ou não, têm natureza alimentar e são necessários para a sobrevivência da pessoa humana, desenvolvendo, dessa forma, a manutenção do trabalho humano e autônomo, como é o caso do advogado. 
Conclui-se, dessa maneira, que a Lei no $13.467 / 17$ alterou a CLT para introduzir, ao processo do trabalho, o princípio da sucumbência, aplicando-se subsidiariamente o CPC. Assim, acredita-se que a referida modificação no processo trabalhista trará benefícios especialmente aos advogados, que passarão a receber honorários sucumbenciais.

\section{ASPECTOS POSITIVOS E NEGATIVOS DA CONDENAÇÃO EM HONORÁRIOS SUCUMBENCIAIS DE ACORDO COM O TEXTO DA NOVA REFORMA TRABALHISTA}

Uma vez apresentados os distintos posicionamentos acerca da constitucionalidade do dispositivo que possibilitou, como regra, a condenação de honorários sucumbenciais na Justiça do Trabalho, cabe analisar, de forma breve, alguns aspectos positivos e negativos relativos à tal alteração.

No que se refere ao aspecto positivo a se observar com todas as alterações, um dos principais é que, caso a parte sucumbente condenada em honorários não tenha obtido em juízo, ainda que em outro processo, créditos capazes de suportar as obrigações decorrentes da sucumbência, a dívida da condenação sucumbencial fica suspensa durante dois anos e, caso continue em situação de hipossuficiência, extingue-se a obrigação.

É muito importante observar como o texto trabalhista vem a favorecer o empregado hipossuficiente, uma vez que, mesmo tendo criado essa regra de forma subsidiária ao Código de Processo Civil, estipulou um prazo para cessar a condenação bem inferior a este, uma vez que o CPC prevê que a condenação fica suspensa durante cinco anos, três anos a mais do que prevê a nova reforma trabalhista.

Isso, com certeza, irá favorecer muito ao empregado, posto que dificilmente uma pessoa deixará a condenação de hipossuficiência no interstício de dois anos.

Com relação aos pontos negativos da reforma quanto ao tema abordado, um dos que mais chama a atenção é a hipótese de procedência parcial, uma vez que o juízo condenará em honorários sucumbenciais ambas as partes, sendo proibida a compensação entre honorários.

Dessa maneira, o empregado, quando figurar no polo ativo da demanda, deverá ter muito cuidado com o que realmente vai pedir na inicial, uma vez que, caso o juiz indefira seu pedido em sentença, o mesmo arcará com os custos processuais referentes às custas judiciais e honorários sucumbenciais.

Apesar de ser um ponto negativo no que contende aos custos para o reclamante, tal novidade, trazida na nova lei trabalhista, com certeza irá propiciar um grande conforto na considerável demanda da justiça laboral, posto que o reclamante, ao entrar com uma ação trabalhista, deverá ser orientado pelo seu procurador a relatar e pedir apenas aquilo que lhe foi lesado, sob pena de arcar com altos valores e podendo acabar saindo com um saldo negativo no resultado final da lide.

\section{CONSIDERAÇÕES FINAIS}

O presente artigo buscou analisar as alterações legislativas trazidas pela Lei $n$ 0 13.467/17 referentes aos honorários sucumbenciais. Para isso, foram examinadas cada uma das modificações no pagamento dos honorários sucumbenciais advocatícios.

Ademais, este artigo buscou elucidar algumas questões controvertidas a respeito dos honorários sucumbenciais, as quais ainda estão sendo discutidas e pacificadas pela doutrina e jurisprudência pátria.

Diante do exposto, percebe-se que a reforma trabalhista pouco deixou a desejar quanto a esse ponto trazido em seu corpo. De fato, os honorários sucumbenciais são necessários nessa seara do direito em todas as suas relações, inexistindo inconstitucionalidade, e, pelo contrário, protegendo direitos fundamentais previstos na Lei Maior.

Ainda há, porém, muito a ser considerado acerca da reforma trabalhista, principalmente levando em conta os diversos pontos de alterações na legislação trabalhista trazidos com a Lei no 13.467 de 2017 e os prováveis impactos e mudanças que a mesma surtirá nas rotinas de trabalho e emprego dos setores produtivos do país.

Os doutrinadores, em suas obras posteriores à reforma trabalhista, ainda mostram-se bastante silentes quanto ao conteúdo abordado neste artigo, não manifestando ou manifestando pequenos comentários a respeito da temática. 
Alguns apenas apresentam a literalidade dos novos artigos, outros atentam-se a tecer comentários mais aprofundados, apontando, inclusive, a (in)constitucionalidade do artigo 791-A da CLT.

Sendo assim, tentou-se, por meio dos comentários deste artigo, atualizar os leitores e a sociedade como um todo sobre as novas regras a respeito da condenação em honorários sucumbências na justiça do trabalho, que, inclusive, já se encontra em vigor. Somente no futuro, todavia, poderá se notar quais os impactos que as alterações trazidas pela Lei $\mathrm{n}$ 0 13.467/17 acarretarão aos honorários advocatícios sucumbenciais, porém algumas ideias já foram trazidas neste breve escrito.

\section{REFERÊNCIAS}

AMORIM, Erica Ribeiro Guimarães. As alterações trazidas pela Lei no 13.467/17 ao acesso à justiça: os impactos da reforma trabalhista à efetividade da Justiça do Trabalho no Brasil. Direito do trabalho e meio ambiente do trabalho I. Organização Conpedi/Ufba. Disponível em: https://www.conpedi.org.br/publicacoes/0ds65m46/4s56827c/fTp824WAm8qhpt22.pdf. Acesso em: 3 ago. 2018.

BRASIL. Superior Tribunal de Justiça. Recurso Especial № 706331. Disponível em: https://stj.jusbrasil.com.br/jurisprudencia/7198271/recurso-especial-resp-706331-pr-2004-0168203-0-stj/relatorio-e-voto-12948038. Acesso em: 20 out. 2017a.

BRASIL. Superior Tribunal de Justiça. Recurso Especial no 1152218. Disponível em: https://www.jusbrasil.com.br/diarios/documentos/144439769/recurso-especial-n-1152218-rs-do-stj. Acesso em: 20 out. 2017a.

BRASIL. Amatra 9a Região. Honorários de Sucumbência Recíproca na Justiça do Trabalho - Lei № 13.467/2017: Segurança Jurídica, Aplicação Intertemporal e Critérios de Fixação. Disponível em: http://www.amatra9.org.br/honorarios-de-sucumbencia-reciproca-na-justica-do-trabalho-lei-no-13-4672017-seguranca-juridica-aplicacao-intertemporal-e-criterios-de-fixacao-eduardo-milleo-baracat/. Acesso em: 20 maio 2018.

CASTRO, Antônio Escosteguy. O acesso à Justiça e as alterações trazidas pela Lei 13.467/17: a reforma trabalhista e os seus impactos no processo do trabalho. 2017. Disponível em: https://www.sul21.com.br/jornal/restricao-ao-acesso-justica-na-lei-13-46717/. Acesso em: 23 set. 2018.

DELGADO, Mauricio Godinho; DELGADO, Gabriela Neves. A reforma trabalhista no Brasil: com os comentários à Lei no 13.467/2017. São Paulo: LTR, 2017.

LEITE, Carlos Henrique Bezerra. Curso de Direito Processual do Trabalho. 15. ed. São Paulo: Saraiva, 2017.

LEITE, Carlos Henrique Bezerra. Curso de Direito Processual do Trabalho. 16. ed. São Paulo: Saraiva, 2018.

MANFREDINI, Aryanna; SARAIVA, Renato. Processo do trabalho. 12. ed. Salvador: Juspodivm, 2016.

MARTINS. Sérgio Pinto. Direito Processual do Trabalho. 38. ed. São Paulo: Saraiva, 2016.

NEVES, Daniel Amorim Assumpção. Manual de Direito Processual Civil. 8. ed. Salvador: Juspodivm, 2016.

PEREIRA. Leone. Manual de processo do trabalho. 4. ed. São Paulo: Saraiva, 2017.

PEREIRA. Leone. Manual de processo do trabalho. 5. ed. São Paulo: Saraiva, 2018.

TEIXEIRA FILHO, Manoel Antônio. O processo do trabalho e a reforma trabalhista: as alterações introduzidas no processo do trabalho pela Lei n. 13.467/2017. São Paulo: LTR Editora, 2017. 